$127-134$

\title{
Validation of a clinicopathological score for the prediction of post-surgical evolution of pituitary adenoma: retrospective analysis on 566 patients from a tertiary care centre
}

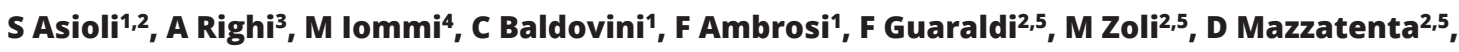 \\ M Faustini-Fustini ${ }^{2}$, P Rucci ${ }^{4}$, C Giannini ${ }^{6}$ and M PFoschini $^{1}$ \\ ${ }^{1}$ Department of Biomedical and Neuromuscular Sciences, Section of Anatomic Pathology 'M. Malpighi' at Bellaria \\ Hospital, University of Bologna, ${ }^{2}$ Pituitary Unit - Center for the Diagnosis and Treatment of Hypothalamic and \\ Pituitary Diseases, IRCCS Istituto delle Scienze Neurologiche di Bologna, ${ }^{3}$ Department of Pathology, IRCCS Rizzoli \\ Institute, ${ }^{4}$ University of Bologna, Unit of Hygiene and Biostatistics, ${ }^{5}$ Department of Biomedical and Neuromotor \\ Sciences (DIBINEM), University of Bologna, Bologna, Italy, and ${ }^{6}$ Department of Pathology \& Laboratory Medicine, \\ Mayo Clinic, Rochester, Minnesota, USA
}

Correspondence should be addressed to A Righi

Email

alberto.righi@ior.it

\begin{abstract}
Objective and design: A clinicopathological score has been proposed by Trouillas et al. to predict the evolution of pituitary adenomas. Aim of our study was to perform an independent external validation of this score and identify other potential predictor of post-surgical outcome.

Methods: The study sample included 566 patients with pituitary adenomas, specifically $253 \mathrm{FSH} / \mathrm{LH}$-secreting, 147 GH-secreting, 85 PRL-secreting, 72 ACTH-secreting and 9 TSH-secreting tumours with at least 3-year post-surgical follow-up.

Results: In 437 cases, pituitary adenomas were non-invasive, with low (grade 1a: 378 cases) or high (grade 1b: 59 cases) proliferative activity. In 129 cases, tumours were invasive, with low (grade 2a: 87 cases) or high (grade 2b: 42 cases) proliferative activity. During the follow-up (mean: 5.8 years), 60 patients developed disease recurrence or progression, with a total of 130 patients with pituitary disease at last follow-up. Univariate analysis demonstrated a significantly higher risk of disease persistence and recurrence/progression in patients with PRL-, ACTH- and FSH/LH-secreting tumours as compared to those with somatotroph tumours, and in those with high proliferative activity (grade $1 \mathrm{~b}$ and $2 \mathrm{~b}$ ) or $>1 \mathrm{~cm}$ diameter. Multivariate analysis confirmed tumour type and grade to be independent predictors of disease-free-survival. Tumour invasion, $\mathrm{Ki}-67$ and tumour type were the only independent prognostic factors of disease-free survival. Conclusions: Our data confirmed the validity of Trouillas' score, being tumour type and grade independent predictors of disease evolution. Therefore, we recommend to always consider both features, together with tumour histological subtype, in the clinical setting to early identify patients at higher risk of recurrence.
\end{abstract}

\section{Introduction}

Pituitary adenomas (PAs) are relatively common intracranial tumours arising from the adenohypophysis and accounting for $10-15 \%$ of all intracranial neoplasms $(1,2,3,4)$. Although typically benign under a histological point of view, they can (c) 2019 European Society of Endocrinology Printed in Great Britain exhibit an aggressive clinical and radiological behaviour, characterised by rapid growth with gross invasion of the surrounding tissues, together with resistance, or early recurrence, after treatment $(4,5,6,7,8)$. Therefore, it has 
been recently proposed to rename these lesions as pituitary neuroendocrine tumours (PitNET) (3). Only rarely they metastasise through the cerebrospinal fluid or systemically and are then considered 'pituitary carcinomas' $(6,7)$.

The term 'atypical adenoma' defined in the $2004 \mathrm{WHO}$ classification (8) as an 'adenoma with high mitotic index, Ki-67 labelling index (LI) $\geq 3 \%$ and strong nuclear p53 protein immunoexpression' was abandoned in the 2017 WHO classification, since a definite correlation between histological diagnosis and clinical behaviour could not be established (1). However, the 2017 WHO classification, still suggests to divide PAs between 'low' and 'high risk' based on their proliferative activity (1). Recently, Trouillas et al. (5) proposed a clinicopathological score based on the evidence of tumour invasion and proliferation and identifying the following features as risk criteria: mitoses $\geq 2 / 10 \mathrm{HPF}$, Ki-67 $\geq 3 \%$ and p53 expression $>10$ strongly positive nuclei/10 HPF. Since in most of the cases invasion can only be evaluated by MRI and/or surgical findings, the proposed score requires a multidisciplinary approach involving the pathologist, the radiologist, the endocrinologist and the neurosurgeon. In brief, the authors proposed a '5 grades score': grade 1a, non-invasive and low proliferative tumour; grade $1 \mathrm{~b}$, non-invasive and high proliferative tumour; grade 2a, invasive and low proliferative tumour; grade $2 \mathrm{~b}$, invasive and high proliferative tumour and grade 3, metastatic tumour (cerebrospinal or systemic metastases). The score was validated by the same group on a retrospective multicentric case-control study, which included 410 patients with 8-year post-operative follow-up (5). Tumour invasion with high proliferation were predictors of aggressive clinical behaviour, in terms of disease-free survival and recurrence/progression-free status (5). These preliminary findings were confirmed by a subsequent prospective independent cohort of 240 patients with a mean follow-up of 3.5 years (2).

The aim of our study was to analyse several histopathological, clinical and radiological criteria in our large cohort of patients operated for PAs to validate the classification proposed by Trouillas et al. (5) and to identify other potential factors predicting post-surgical disease evolution.

\section{Subjects and methods}

\section{Study sample}

The study included all consecutive patients operated of PAs at the Pituitary Unit, IRCCS Istitutodelle Scienze Neurologiche, Bologna, Italy, between January 1998 and
December 2012. Inclusion criteria were (1) availability of tissue slides and paraffin blocks of sufficient size to allow morphological and immunohistochemical characterisation; (2) no history of radiation therapy before or after surgery in the absence of a demonstrated tumour progression; (3) available pre- and post-surgery clinical information, including complete basal and stimulated (when appropriate) hormonal evaluation and neuroimaging data and (4) minimum post-surgical follow-up of 3 years. Existing slides were retrieved from the pathology archives and reviewed.

All PAs were removed by endoscopic endonasal surgery by two expert neurosurgeons ( $\mathrm{M} \mathrm{Z}, \mathrm{D} \mathrm{M})$. Onehundred and eight cases had been previously reported in other studies. For these cases, we retrieved clinical information from the last follow-up, dating at the time of publication, with the same methods applied to the investigation of new cases (see 'Materials and methods' section). For all cases, histological and radiological revision was performed applying the criteria suggested by Trouillas' et al. $(9,10,11,12)$.

According to pre-operative hormonal and clinical features, tumours were classified into clinically 'functioning' and 'non-functioning'. Based on their size in the pre-operative MRI, tumours were classified into 'micro-' $(<10 \mathrm{~mm})$ and 'macroadenomas' $(\geq 10 \mathrm{~mm})$. Tumour invasion was suspected on pre-operative MRI for cases with grade of Knosp $>3$, although only cases with demonstrated invasion of the cavernous sinus and/ or sphenoidal bone during surgical exploration and/or pathological evaluation were considered 'invasive' (13).

Follow-up monitoring included post-operative MRI, endocrinological and neurological evaluations, performed at 3 months after surgery and then at variable intervals, depending on the clinical, biochemical and neuroradiological findings. The degree of tumour removal was evaluated on post-operative MRI and defined as 'radical' in the absence of visible remnant; 'subtotal' for remnant $<20 \%$ of the original mass or 'partial' if $>20 \%$ of the original mass. Normalisation of hormone hypersecretion (or disease control) was defined according to post-operative basal hormone secretion, and stimulated/inhibited function, whenever necessary. In case of persistent hormone hypersecretion, targeted medial therapy was prescribed. 'Surgical cure' was defined by radical resection in non-functioning tumours, together with the normalisation of hormone secretion in functioning ones. Conversely, non-functioning tumours with a stable remnant at follow-up or functioning ones with control of hormonal secretion by medical therapy 
were considered 'controlled'. 'Relapse' was defined as the recurrence or increase of remnant dimensions in non-functioning PAs or the recurrence of hormone hypersecretion (treatment escape in case of medical treatment) in functioning tumours $(5,9)$.

The present study was approved by an inter-hospital Ethical Committee of Bologna city (protocol number CE17143, dating February 20th, 2018). Consent has been obtained from each patient or subject after full explanation of the purpose and nature of all procedures used.

\section{Immunohistochemistry}

All slides were reviewed and classified by three expert pituitary pathologists (A S, A R and M P F) according the recently published WHO classification of endocrine organs tumours (1). Tumours expressing multiple hormones were classified according to the mostly represented hormone immunoreactivity (5). Ki-67 LI was expressed as the percentage of tumour cells with positive nuclei. Following the criteria proposed by Trouillas et al. (5), p53 protein stain was considered positive for $>10$ strongly positive nuclei per 10 high power fields (HPF $0.30 \mathrm{~mm}^{2}, 400 \times$ magnification) (5). Similar to other endocrine neoplasms, Ki-67 LI and p53 detection was based on the evaluation of cells in the areas with the highest nuclear labelling ('hotspots') . A digital camera (Olympus Q-colour 3, Tokyo, Japan) with area-based image analysis software (Dot-Slide 1.2 version) was used to minimise inter- and intra-observer variability. Immunostained sections were screened under optical microscope and the areas containing the greatest number of Ki-67-stained and p53-stained nuclei were outlined with a slide marker, allowing easy localisation during image analysis, as previously described (9). PAs subtyping by immunohistochemistry was performed according to the criteria proposed by Trouillas et al. and recently incorporated in the WHO classification $(1,5)$. Silent ACTH tumours $(n=14)$ and one ACTH tumour secondary to Nelson syndrome were grouped together with ACTH adenomas.

\section{Statistical analysis}

Categorical variables were summarised using absolute and relative frequencies, while quantitative variables were summarised using mean and standard deviation.

Disease-free survival distribution was estimated using Kaplan-Meier product limit.

Gender, age (treated as a continuous variable), tumour size, tumour type, mitotic index, invasion, Ki-67 LI, p53 expression and tumour grade were analysed as possible predictors of outcomes. The log-rank test was used to compare survival curves between groups. Cox proportional hazards models were used to estimate the hazard ratio and confidence intervals for each risk factor. The proportional hazards assumption was tested using Schoenfeld residuals - Multivariable Cox proportional hazards regression models were used to adjust for explanatory variables.

For all tests, significance was defined as $P<0.05$. Statistical analysis was performed using IBM SPSS version 23.0 and Stata 12.

\section{Results}

\section{Demographic, clinical and pathologic features}

Main sample demographic, clinical and pathologic features at baseline and follow-up period are summarised in Table 1. The study sample included 566 patients (310 F, 54.8\%) with PAs treated by trans-sphenoidal endoscopic endonasal surgery. Age at the time of first surgery was $49.8 \pm 15.5$ years; median 50 ; range $12-85$ ). At the pre-operative MRI, most tumours ( $n=440 ; 77.7 \%$ ) were macroadenomas. According to the previously mentioned criteria, 129 (22.8\%) tumours were considered invasive, with surgical and/or pathological demonstrated invasion of the cavernous $(n=109,19 \%)$ or sphenoid $(n=20 ; 3.5 \%)$ sinus.

Based on the immunohistochemical data, the study sample included 253 FSH/LH-, 147 GH-, 85 PRL-, 72 ACTH(14 silent) and 9 TSH-secreting tumours. The group of $\mathrm{GH}$-secreting tumours was made of 45 sparsely granulated and 83 densely granulated lesions; 17 were mixed GH- and PRL-secreting tumours, while two presented plurihormonal secretion. Two hundred and fifty-three FSH/LH PAs consisted of 183 null cell tumours (of these, 19 were of oncocytic variant) and 70 gonadotroph cell lesions.

A high mitotic index ( $\geq 2$ each $10 \mathrm{HPF}$ ) was found in 107 cases (18.9\%). Mean Ki-67 LI was 2.1\% (range 0.1-21); 105 (18.6\%) cases showed a Ki-67 LI value $\geq 3 \%$. P53 protein expression was positive in $133(23.5 \%)$ cases. According to the Trouillas' classification criteria, 378 (66.8\%) tumours were grade 1a; 59 (10.4\%) grade 1b; $87(15.4 \%)$ grade $2 \mathrm{a}$ and $42(7.4 \%)$ grade $2 \mathrm{~b}$. Tumour grade distribution for each tumour subtype defined by immunohistochemistry is presented in Table 2 .

Mean follow-up was 5.8 years (range 3-17.7 years). During the follow-up period, 60 (10.6\%) patients developed tumour recurrence after apparent gross total resection or disease progression after subtotal surgical resection. 
Table 1 Main sample demographic, clinical and pathologic features at baseline and follow-up.

\begin{tabular}{|c|c|c|c|}
\hline & \multirow[b]{2}{*}{ Total, $\boldsymbol{n}(\%)$} & \multicolumn{2}{|c|}{ Disease-free, $\boldsymbol{n}(\%)$} \\
\hline & & Yes & No \\
\hline \multicolumn{4}{|l|}{ Gender } \\
\hline Male & $256(45.2)$ & $194(44.5)$ & $62(47.7)$ \\
\hline Female & $310(54.8)$ & $242(55.5)$ & $68(52.3)$ \\
\hline Age (years) mean \pm S.D. & $49.8 \pm 15.5$ & $49.9 \pm 15.3$ & $49.2 \pm 16.0$ \\
\hline \multicolumn{4}{|l|}{ Tumour size } \\
\hline Micro & $126(22.3)$ & $108(24.8)$ & $18(13.8)$ \\
\hline Macro & $440(77.7)$ & $328(75.2)$ & $112(86.2)$ \\
\hline \multicolumn{4}{|l|}{ Invasion } \\
\hline No & $437(77.2)$ & $354(81.2)$ & $83(63.8)$ \\
\hline Yes & $129(22.8)$ & $82(18.8)$ & $47(36.2)$ \\
\hline \multicolumn{4}{|l|}{ Tumor type } \\
\hline $\mathrm{GH}$ & $147(26)$ & $121(27.8)$ & $26(20)$ \\
\hline PRL & 85 (15) & 59 (13.5) & $26(20)$ \\
\hline ACTH & $72(12.7)$ & $55(12.6)$ & $17(13.1)$ \\
\hline TSH & $9(1.6)$ & $8(1.8)$ & $1(0.7)$ \\
\hline FSH/LH & $253(44.7)$ & $193(44.3)$ & $60(46.2)$ \\
\hline \multicolumn{4}{|l|}{ Mitoses } \\
\hline$<2$ & $459(81.1)$ & $363(83.3)$ & $96(73.8)$ \\
\hline$\geq 2$ & $107(18.9)$ & 73 (16.7) & $34(26.2)$ \\
\hline \multicolumn{4}{|l|}{ Ki-67 } \\
\hline$<3 \%$ & $461(81.4)$ & $373(85.6)$ & $88(67.7)$ \\
\hline$\geq 3 \%$ & $105(18.6)$ & $63(14.4)$ & $42(32.3)$ \\
\hline \multicolumn{4}{|l|}{ p53 } \\
\hline Negative & $433(76.5)$ & $342(78.4)$ & $91(70)$ \\
\hline Positive & $133(23.5)$ & $94(21.6)$ & $39(30)$ \\
\hline \multicolumn{4}{|l|}{ Grade } \\
\hline 1a: Non-invasive & $378(66.8)$ & $313(71.8)$ & $65(50)$ \\
\hline 1b: Non-invasive, proliferative & $59(10.4)$ & $41(9.4)$ & $18(13.8)$ \\
\hline 2a: Invasive & $87(15.4)$ & $66(15.1)$ & $21(16.2)$ \\
\hline 2b: Invasive, proliferative & $42(7.4)$ & $16(3.7)$ & $26(20)$ \\
\hline
\end{tabular}

The mean time of recurrence/progression was 5.4 years (range 4 months to 17.5 years). At the last follow-up, 130 (22.9\%) patients showed disease persistence, while the remaining were disease free.

\section{Disease-free survival (DFS)}

The disease-free survival distribution is summarised in Table 3ref. cat., reference category. Four, six, eight and ten-year DFS was 86.8, 80.9, 75.1 and 63.4\%, respectively. The disease-free survival, stratified by tumour subtype is presented in Table 4.

Univariate Cox regression models on the determinants of disease outcome showed that patients with macroadenoma had a $81 \%$ higher risk of persistent disease after surgery compared with patients with microadenoma $(\mathrm{HR}=1.810, P=0.02)$ and that patients with invasive tumours had a higher risk of recurrence/ progression than patients with non-invasive tumours $(\mathrm{HR}=2.258, \quad P<0.001)$. A significantly higher risk of persistent disease after surgery was found in patients with PRL- $(\mathrm{HR}=2.968, P<0.001)$, ACTH- $(\mathrm{HR}=2.336, P=0.009)$ and FSH/LH-secreting $(\mathrm{HR}=2.276, P=0.001)$ tumour type compared with patients with somatotroph tumour. Tumours with a number of mitoses $\geq 2 / 10$ HPF had a higher the risk of recurrence/progression as compared with those with a lower number of mitoses $(\mathrm{HR}=2.215$, $P<0.001)$. Patients with Ki-67 LI $\geq 3 \%$ and with high

Table 2 Tumour grade distribution for each tumour subtype defined by immunohistochemistry.

\begin{tabular}{|c|c|c|c|c|c|}
\hline \multirow[b]{2}{*}{ Grade } & \multicolumn{5}{|c|}{ Tumour subtype } \\
\hline & $\mathrm{GH}(n=147)$ & $\operatorname{PRL}(n=85)$ & $\mathrm{ACTH}(n=72)$ & $\mathrm{FSH} / \mathrm{LH}(n=253)$ & $\mathrm{TSH}(n=9)$ \\
\hline $1 a$ & 102 (69.4\%) & 45 (52.9\%) & $47(65.3 \%)$ & $179(70.7 \%)$ & $5(55.6 \%)$ \\
\hline $1 \mathrm{~b}$ & $12(8.2 \%)$ & $12(14.1 \%)$ & $15(20.8 \%)$ & $19(7.5 \%)$ & $1(11.1 \%)$ \\
\hline $2 a$ & $25(17 \%)$ & $15(17.6 \%)$ & $4(5.6 \%)$ & $40(15.9 \%)$ & $3(33.3 \%)$ \\
\hline $2 b$ & $8(5.4 \%)$ & $13(15.4 \%)$ & $6(8.3 \%)$ & $15(5.9 \%)$ & 0 \\
\hline
\end{tabular}


Table 3 Predictors of disease-free status over the entire follow-up as defined by univariate Cox regression models.

\begin{tabular}{|c|c|c|}
\hline & HR $(95 \% \mathrm{Cl})$ & $P$ value \\
\hline \multicolumn{3}{|l|}{ Gender } \\
\hline Male (ref. cat.) & 1 & \\
\hline Female & $0.903(0.640 ; 1.275)$ & 0.564 \\
\hline Age (years) mean \pm S.D. & $1.000(0.989 ; 1.011)$ & 0.992 \\
\hline \multicolumn{3}{|l|}{ Tumour size } \\
\hline Micro (ref. cat.) & 1 & \\
\hline Macro & $1.810(1.099 ; 2.979)$ & 0.020 \\
\hline \multicolumn{3}{|l|}{ Invasion } \\
\hline No (ref. cat.) & 1 & \\
\hline Yes & $2.258(1.575 ; 3.236)$ & $<0.001$ \\
\hline \multicolumn{3}{|l|}{ Tumour type } \\
\hline GH (ref. cat.) & 1 & \\
\hline PRL & $2.968(1.672 ; 5.270)$ & $<0.001$ \\
\hline ACTH & $2.336(1.233 ; 4.426)$ & 0.009 \\
\hline TSH & $1.125(0.151 ; 8.393)$ & 0.909 \\
\hline $\mathrm{FSH} / \mathrm{LH}$ & $2.276(1.389 ; 3.731)$ & 0.001 \\
\hline \multicolumn{3}{|l|}{ Mitoses } \\
\hline$<2$ & 1 & \\
\hline$\geq 2$ & $2.215(1.481 ; 3.312)$ & $<0.001$ \\
\hline \multicolumn{3}{|l|}{$\mathrm{Ki}-\overline{67}$} \\
\hline$<3 \%$ & 1 & \\
\hline$\geq 3 \%$ & $2.293(2.005 ; 4.260)$ & $<0.001$ \\
\hline \multicolumn{3}{|l|}{ P53 } \\
\hline Negative & 1 & \\
\hline Positive & $1.696(1.162 ; 2.478)$ & 0.006 \\
\hline \multicolumn{3}{|l|}{ Grade } \\
\hline 1a (ref. cat.) & 1 & \\
\hline $1 \mathrm{~b}$ & $2.597(1.531 ; 4.408)$ & $<0.001$ \\
\hline $2 a$ & $1.579(0.963 ; 2.592)$ & 0.070 \\
\hline $2 b$ & $5.516(3.471 ; 8.766)$ & $<0.001$ \\
\hline
\end{tabular}

expression of p53 protein had a higher risk of recurrence/ progression as compared with patients with Ki-67 LI $<3 \%(\mathrm{HR}=2.293, P<0.001)$ and with low p53 expression $(\mathrm{HR}=1.696, P=0.006)$, respectively. The hazard ratios for grades $1 \mathrm{~b}$ and $2 \mathrm{~b}$ were significantly higher compared with grade 1a $(\mathrm{HR}=2.597, P<0.001 ; \mathrm{HR}=5.516, P<0.001)$. No statistically effect of gender of age on DFS was found (Table 3).

According to multivariate Cox regression analysis, which included tumour size, type and grade (the last incorporating invasiveness and proliferation) (Table 5A), tumour type and grade remained independent predictors of DFS, while tumour size was not. In particular, tumour grade $1 b$ and $2 b$ were independent predictors of worse outcome $(\mathrm{HR}=2.441, P=0.001$ for grade $1 \mathrm{~b} ; \mathrm{HR}=5.005$, $P<0.001$ for grade $2 \mathrm{~b}$ ) .

Considering every single variable, multivariate Cox regression analysis showed tumour invasion $(\mathrm{HR}=1.926$; $P=0.001), \quad \mathrm{Ki}-67 \geq 3 \%(\mathrm{HR}=2.290 ; P=0.003)$ and type to be independent prognostic factor of DFS (Table $5 \mathrm{~B}$ ). Specifically, the risk of recurrence/progression was

significantly higher in PRL- $(\mathrm{HR}=2.428 ; P=0.003)$, ACTH$(\mathrm{HR}=2.242 ; P=0.018)$ and $\mathrm{FSH} / \mathrm{LH}$-secreting tumours $(\mathrm{HR}=2.377 ; P=0.002)$ as compared with $\mathrm{GH}$ tumour. The grade distribution for sparsely and densely granulated GH-secreting tumours is presented in Table 6. Finally, sparsely granulated PAs were associated with a worse prognosis as compared to densely granulated $(P=0.005$ according to Pearson chi-square test).

\section{Discussion}

Our study demonstrated the role of histological type, grade of invasion and proliferation in the determination of the post-surgical outcome of PAs based on the retrospective analysis of more than 500 cases primary treated with surgery.

PAs are the most common pituitary disorders and are, by definition, histologically benign. However, in a variable percentage of cases, they present an aggressive behaviour with the invasion of surrounding structures, together with partial/no response to treatment or recurrence after surgery, and, more rarely, distant metastases (pituitary carcinomas) (1). Therefore, the identification of prognostic factors of outcome in this field would be of primary importance to provide patients the most appropriate follow-up based on predefined risk of recurrence/resistance to treatment. Unfortunately, to date, studies focusing on this issue are scanty.

In 2004, the WHO classification of Tumours of Endocrine organs proposed the distinction between 'typical' and 'atypical' adenomas, that has been removed

Table 4 Disease-free survival according to tumour subtype.

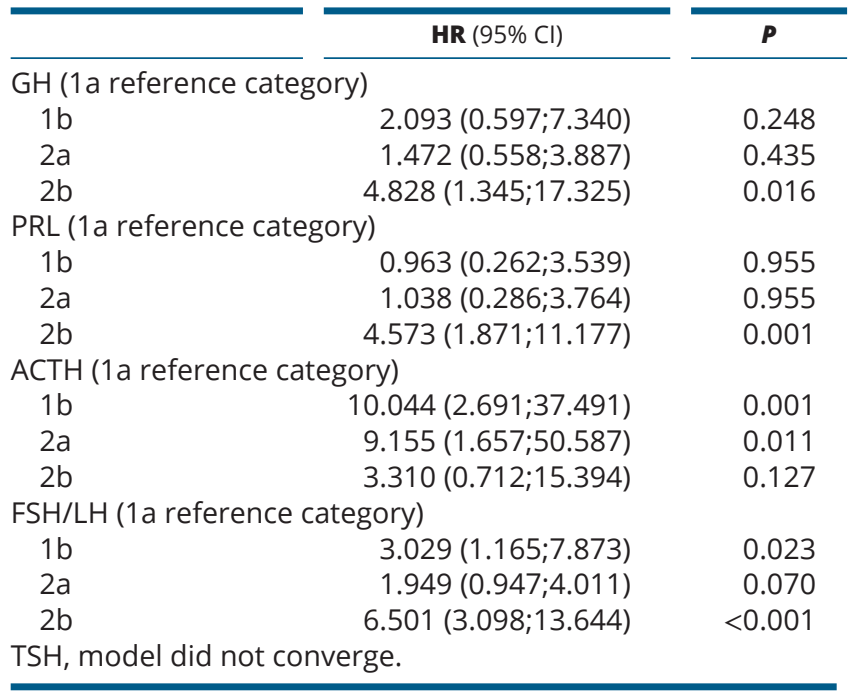


Table 5 Predictors of disease-free status over the entire follow-up as defined by multivariate Cox regression analysis including tumour size, type, grade (incorporating invasiveness and proliferation), tumour size, type, number of mitoses, Ki-67 index and p53 expression.

\begin{tabular}{|c|c|c|}
\hline & HR $(95 \% \mathrm{Cl})$ & $\boldsymbol{P}$ \\
\hline \multicolumn{3}{|c|}{ A: Independent predictors of DFS } \\
\hline \multicolumn{3}{|c|}{ Tumour size } \\
\hline Micro & 1 & \\
\hline Macro & $1.251(0.687 ; 2.281)$ & 0.464 \\
\hline \multicolumn{3}{|l|}{ Tumour type } \\
\hline $\mathrm{GH}$ & 1 & \\
\hline PRL & $2.386(1.328 ; 4.285)$ & 0.004 \\
\hline ACTH & $2.101(1.076 ; 4.102)$ & 0.03 \\
\hline TSH & $0.861(0.115 ; 6.468)$ & 0.884 \\
\hline $\mathrm{FSH} / \mathrm{LH}$ & $2.302(1.344 ; 3.943)$ & 0.002 \\
\hline \multicolumn{3}{|l|}{ Grade } \\
\hline $1 a$ & 1 & \\
\hline $1 b$ & $2.441(1.419 ; 4.198)$ & 0.001 \\
\hline $2 a$ & $1.661(0.995 ; 2.773)$ & 0.052 \\
\hline $2 b$ & $5.005(3.030 ; 8.265)$ & $<0.001$ \\
\hline \multicolumn{3}{|c|}{ B: Independent prognostic factors of DFS } \\
\hline \multicolumn{3}{|l|}{ Size } \\
\hline Micro & 1 & \\
\hline Macro & $1.300(0.710 ; 2.382)$ & 0.395 \\
\hline \multicolumn{3}{|l|}{ Invasion } \\
\hline No & 1 & \\
\hline Yes & $1.926(1.301 ; 2.850)$ & 0.001 \\
\hline \multicolumn{3}{|l|}{ Tumor type } \\
\hline $\mathrm{GH}$ & 1 & \\
\hline PRL & $2.428(1.348 ; 4.372)$ & 0.003 \\
\hline ACTH & $2.242(1.146 ; 4.387)$ & 0.018 \\
\hline $\mathrm{FSH} / \mathrm{LH}$ & $2.377(1.386 ; 4.078)$ & 0.002 \\
\hline \multicolumn{3}{|l|}{ Mitoses } \\
\hline$<2$ & 1 & \\
\hline$\geq 2$ & $1.101(0.654 ; 1.852)$ & 0.717 \\
\hline \multicolumn{3}{|l|}{$\mathrm{Ki}-\overline{67}$} \\
\hline$<3 \%$ & 1 & \\
\hline$\geq 3 \%$ & $2.290(1.333 ; 3.932)$ & 0.003 \\
\hline \multicolumn{3}{|c|}{ 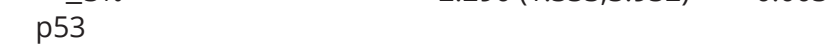 } \\
\hline Negative & 1 & \\
\hline Positive & $0.933(0.586 ; 1.485)$ & 0.769 \\
\hline
\end{tabular}

in the 2017 WHO classification for the absence of clinicpathological correlations $(4,8,9,14,15,16,17,18,19$, 20 ), leaving place to the cell lineage origin as a main criteria of classification (1).

Moreover, in the 2004 WHO classification, high mitotic index and a Ki-67 LI $\geq 3 \%$ were considered effective prognostic markers of PAs $(4,5,8,9,14,15,16$, $17,18,19,20,21)$. Expression of p53 was also included among potential outcome predictors (8), but is remained unclear whether its expression was an independent factor of aggressive behaviour because of the different cutoffs used in literature to differentiate tumours with low and high risk of recurrence/progression together with the high inter-observer variability $(1,4,5,9,18)$. Rapid growth, radiological evidence of invasion and high Ki-67 proliferation index were later suggested as features of clinically aggressive tumours, implying a closer follow-up in these cases. Recently, precise cut-off for the number of mitoses and p53 expression have been determined to define tumours at high risk of recurrence $(4,5,8,9,14,15$, $16,17,18,19,20,21)$.

In 2013, Trouillas et al. (5) proposed a clinicopathological classification, based on the evaluation of tumour invasion - defined at MRI and during surgery - and proliferation, through which it was possible to identify '5 grades' of PAs. This classification was validated by the same group by a retrospective study that included 213 patients treated with surgery with a mean postoperative follow-up of 3.5 years (2). The validity of Trouillas' classification to define PAs prognosis has been recently underlined by Lelotte et al. in the setting of gonadotroph tumours (22).

Our retrospective analysis, performed on 566 patients with all histotypes of PAs, confirmed the prognostic value of Trouillas' classification, thus underlying the importance of a grading system that includes indexes of proliferation and invasiveness to predict post-surgical risk of disease persistence and recurrence/progression. In our paper, we assessed the invasiveness of these tumours not basing on the neuroradiological suspect of pre-operative invasion evaluated at MRI, but on the real inspection. Indeed, as stated by Micko et al. we believe that the real advantage of endoscopic endonasal technique is the great possibility to inspect the surgical cavity, achieving a direct evaluation of the real tumour invasion of cavernous sinus or other structures (23). Conversely, it has been demonstrated the any neuroradiological classification to determine the invasiveness of pituitary adenomas, such as Knosp grade, may not perfectly correlate with its real infiltration of cavernous sinus $(23,24)$. Moreover, in line with Trouillas et al. $(5,14)$, we also demonstrated the primary importance of tumour histotype in the prediction of treatment outcome, since it appears the best clinical predictor of diseasefree survival, based on both uni- and multivariate Cox

Table 6 Grade distribution for $\mathrm{GH}$-secreting tumours classified into sparsely and densely.

\begin{tabular}{|c|c|c|}
\hline Grade & Sparsely granulated & Densely granulated \\
\hline $1 a$ & 30 & 60 \\
\hline $1 b$ & 4 & 7 \\
\hline $2 a$ & 8 & 13 \\
\hline $2 b$ & 3 & 3 \\
\hline
\end{tabular}


regression analyses. Specifically, patients with GH-secreting tumours had a significantly lower risk of disease persistence/ recurrence with respect to all other types of PAs.

In our series (for unknown reasons), the ratio between densely $(n=86)$ and sparsely $(n=45)$ granulated somatotroph PAs was 1.86, which is higher than reported in other studies $(4,15,25)$. On the other hand, we confirmed literature data about the more aggressive behaviour of the sparsely granulated variant $(1,6)$, associated with a significantly lower rate of disease-free survival with respect to densely granulated tumours ( $P=0.005$ according to Pearson chi-square test).

A limitation of our study is the relatively short follow-up time (median 5.8 years), since pituitary tumours can take many years to recur or regrow (2). This difference is evident in our lower frequency of recurrence or progression events (10.6\%) and of patients with evidence of disease (22.9\%) compared with the study by Trouillas et al. (mean follow-up 11.1 years, recurrence 30.5\%, persistent disease $52.4 \%)$. Despite this wide difference in terms of follow-up, the Ki-67, p53 and mitotic rate cut-off values proposed by Trouillas et al. (5) are confirmed in our study, and consequently a more precise categorisation of PAs in terms of their values may be possible. In addition, these cut-off values should also simplify and standardise the pathological analysis of adenomas, making comparisons across study cohorts possible. As reported by Raverot et al. (2), this classification should be further refined by other studies considering rarer tumours that those included herein, in particular specific morphological subtypes that have demonstrated to be prone to aggressive behaviour (such as Crooke cell adenomas, silent corticotroph adenoma, plurihormonal PIT1-positive adenoma).

In conclusion, we observed that Trouillas' classification essentially based on tumour proliferation (i.e. mitotic count and Ki-67 LI) and adenoma invasion should be evaluated in individual tumours for identification of clinically aggressive tumours. Tumour grade however is not the only independent parameter to discriminate cases with a high risk of recurrence/progression and of postoperative complete remission and should be integrated with the hormonal subtype.

\section{Declaration of interest}

The authors declare that there is no conflict of interest that could be perceived as prejudicing the impartiality of this study.

\section{Funding}

This work was supported in part by Ricerca Fondamentale Orientata (RFO), University of Bologna, No. RFO-2016 to A S.

\section{Acknowledgements}

The authors thank Dr Giorgio Frank for his fundamental clinical assistance.

\section{References}

1 Osamura RY, Grossman A, Korbonits M, Kovacs K, Lopes MBS, Matsuno A \& Trouillas J. Pituitary adenoma. In World Health Organization Classification of Tumours of Endocrine Organs, 4th ed., pp 14-18. Eds RV Lloyd, RY Osamura, G Kloppel \& J Rosai. Lyon: IARC, 2017.

2 Raverot G, Dantony E, Beauvy J, Vasiljevic A, Mikolasek S, BorsonChazot F, Jouanneau E, Roy P \& Trouillas J. Risk of recurrence in pituitary neuroendocrine tumors: a prospective study using a fivetiered classification. Journal of Clinical Endocrinology and Metabolism 2017102 3368-3374. (https://doi.org/10.1210/jc.2017-00773)

3 Asa SL, Casar-Borota O, Chanson P, Delgrange E, Earls P, Ezzat S, Grossman A, Ikeda H, Inoshita N, Karavitaki N et al. From pituitary adenoma to pituitary neuroendocrine tumor (PitNET): an International Pituitary Pathology Club proposal. Endocrine-Related Cancer 201724 C5-C8. (https://doi.org/10.1530/ERC-17-0004)

4 Saeger W, Ludecke DK, Buchfelder M, Fahlbusch R, Quabbe HJ \& Petersenn S. Pathohistological classification of pituitary tumors: 10 years of experience with the German Pituitary Tumor Registry. European Journal of Endocrinology 2007156 203-216. (https://doi. org/10.1530/eje.1.02326)

5 Trouillas J, Roy P, Sturm N, Dantony E, Cortet-Rudelli C, Viennet G, Bonneville JF, Assaker R, Auger C, Brue T et al. A new prognostic clinicopathological classification of pituitary adenomas: a multicentric case-control study of 410 patients with 8 years postoperative follow-up. Acta Neuropathologica 2013126 123-135. (https://doi.org/10.1007/s00401-013-1084-y)

6 Chatzellis E, Alexandraki KI, Androulakis II \& Kaltsas G. Aggressive pituitary tumors. Neuroendocrinology 2015101 87-104. (https://doi. org/10.1159/000371806)

7 Scheithauer BW, Gaffey TA, Lloyd RV, Sebo TJ, Kovacs KT, Horvath E, Yapicier O, Young WF Jr, Meyer FB, Kuroki T et al. Pathobiology of pituitary adenomas and carcinomas. Neurosurgery 200659 341-353. (https://doi.org/10.1227/01.NEU.0000223437.51435.6E)

8 Lloyd RV, Kovacs K \& Young WF Jr. Tumors of the pituitary. In World Health Organization Classification of Tumors: Pathology and Genetics: Tumors of Endocrine Organs, 3th ed., pp 10-47. Eds RA DeLellis, RV Lloyd, PU Heitz \& C Eng. Lyon: IARC, 2004.

9 Righi A, Agati P, Sisto A, Frank G, Faustini-Fustini M, Agati R, Mazzatenta D, Farnedi A, Menetti F, Marucci G et al. A classification tree approach for pituitary adenomas. Human Pathology 201243 1627-1637. (https://doi.org/10.1016/j.humpath.2011.12.003)

10 Marucci G, Faustini-Fustini M, Righi A, Pasquini E, Frank G, Agati R \& Foschini MP. Thyrotropin-secreting pituitary tumours: significance of 'atypical adenomas' in a series of 10 patients and association with Hashimoto thyroiditis as a cause of delay in diagnosis. Journal of Clinical Pathology 200962 455-459. (https://doi.org/10.1136/jcp.2008.061523)

11 Righi A, Morandi L, Leonardi E, Farnedi A, Marucci G, Sisto A, Frank G, Faustini-Fustini M, Zoli M, Mazzatenta D et al. Galectin-3 expression in pituitary adenomas as a marker of aggressive behavior. Human Pathology 201344 2400-2409. (https://doi.org/10.1016/j. humpath.2013.05.020)

12 Righi A, Faustini-Fustini M, Morandi L, Monti V, Asioli S, Mazzatenta D, Bacci A \& Foschini MP. The changing faces of corticotroph cell adenomas: the role of prohormone convertase 1/3. Endocrine 201756 286-297. (https://doi.org/10.1007/s12020-016-1028-0)

13 Knosp E, Steiner E, Kitz K \& Matula C. Pituitary adenomas with invasion of the cavernous sinus space: a magnetic resonance imaging classification compared with surgical findings. Neurosurgery 199333 610-617. 
14 Raverot G, Vasiljevic A, Jouanneau E \& Trouillas J. A prognostic clinicopathologic classification of pituitary endocrine tumors. Endocrinology and Metabolism Clinics of North America 201544 11-18. (https://doi.org/10.1016/j.ecl.2014.10.001)

15 Miermeister CP, Petersenn S, Buchfelder M, Fahlbusch R, Lüdecke DK, Hölsken A, Bergmann M, Knappe HU, Hans VH, Flitsch J et al. Histological criteria for atypical pituitary adenomas - data from the German pituitary adenoma registry suggests modifications. Acta Neuropathologica Communications 201519 50. (https://doi. org/10.1186/s40478-015-0229-8)

16 Gejman R, Swearingen B \& Hedley-Whyte ET. Role of Ki-67 proliferation index and p53 expression in predicting progression of pituitary adenomas. Human Pathology 200839 758-766. (https://doi. org/10.1016/j.humpath.2007.10.004)

17 Chiloiro S, Bianchi A, Doglietto F, de Waure C, Giampietro A, Fusco A, Iacovazzo D, Tartaglione L, Di Nardo F, Signorelli F et al. Radically resected pituitary adenomas: prognostic role of Ki 67 labeling index in a monocentric retrospective series and literature review. Pituitary 201417 267-276. (https://doi.org/10.1007/s11102-013-0500-6)

18 Wierinckx A, Auger C, Devauchelle P, Reynaud A, Chevallier P, Jan M, Perrin G, Fevre-Montange M, Rey C, Figarella-Branger D et al. A diagnostic marker set for invasion, proliferation, and aggressiveness of prolactin pituitary tumors. Endocrine-Related Cancer 200714 887-900. (https://doi.org/10.1677/ERC-07-0062)

19 Noh TW, JeongHJ, Lee MK, Kim TS, Kim SH \& Lee EJ. Predicting recurrence of nonfunctioning pituitary adenomas. Journal of Clinical Endocrinology and Metabolism 200994 4406-4413. (https://doi. org/10.1210/jc.2009-0471)
20 Zada G, Lin N \& Laws ER Jr. Patterns of extrasellar extension in growth hormone-secreting and nonfunctional pituitary macroadenomas. Neurosurgical Focus 201029 E4. (https://doi.org/10. 3171/2010.7.FOCUS10155)

21 Del Basso De Caro M, Solari D, Pagliuca F, Villa A, Guadagno E, Cavallo LM, Colao A, Pettinato G \& Cappabianca P. Atypical pituitary adenomas: clinical characteristics and role of ki-67 and p53 in prognostic and therapeutic evaluation. A series of 50 patients. Neurosurgical Review 201740 105-114. (https://doi.org/10.1007/s10143-016-0740-9)

22 Lelotte J, Mourin A, Fomekong E, Michotte A, Raftopoulos C \& Maiter D. Both invasiveness and proliferation criteria predict recurrence of non-functioning pituitary macroadenomas after surgery: a retrospective analysis of a monocentric cohort of 120 patients. European Journal of Endocrinology 2018178 237-246. (https://doi.org/10.1530/EJE-17-0965)

23 Micko AS, Wöhrer A, Wolfsberger S \& Knosp E. Invasion of the cavernous sinus space in pituitary adenomas: endoscopic verification and its correlation with an MRI-based classification. Journal of Neurosurgery 2015 122 803-811. (https://doi.org/10.3171/2014.12.JNS141083)

24 Zoli M, Milanese L, Bonfatti R, Sturiale C, Pasquini E, Frank G \& Mazzatenta D. Cavernous sinus invasion by pituitary adenomas: role of endoscopic endonasal surgery. Journal of Neurosurgical Sciences $2016 \mathbf{6 0} 485-494$

25 Nagata Y, Inoshita N, Fukuhara N, Yamaguchi-Okada M, Nishioka H, Iwata T Yoshimoto K \& Yamada S. Growth hormoneproducing pituitary adenomas in childhood and young adulthood: clinical features and outcomes. Pituitary 201821 1-9. (https://doi. org/10.1007/s11102-017-0836-4)

Received 11 September 2018

Revised version received 20 November 2018

Accepted 26 November 2018 